\section{Exposé of misleading claims that male circumcision will increase HIV infections in Africa}

\author{
Brian J. Morris, ${ }^{1}$ Jake H. Waskett, ${ }^{2}$ \\ Ronald H. Gray, ${ }^{3}$ Daniel T. Halperin, ${ }^{4}$ \\ Richard Wamai, ${ }^{5}$ Bertran Auvert, 6 \\ Jeffrey D. Klausner ${ }^{7}$ \\ ${ }^{1}$ School of Medical Sciences, University \\ of Sydney, Sydney, Australia; \\ ${ }^{2}$ Circumcision Independent Reference and \\ Commentary Service, Radcliffe, \\ Manchester, UK; ${ }^{3}$ Bloomberg School of \\ Public Health, Johns Hopkins University, \\ Baltimore, MD, USA; ${ }^{4}$ Department of \\ Global Health and Population, Harvard \\ School of Public Health, Boston, MA, \\ USA; ${ }^{5}$ Department of African-American \\ Studies, Northeastern University, Boston, \\ MA, USA; 'INSERM-UVSQ U1018, \\ Villejuif, France; ${ }^{7}$ Divisions of AIDS \& \\ Infectious Diseases, University of \\ California, San Francisco, CA, USA
}

\section{Abstract}

Despite over two decades of extensive research showing that male circumcision protects against heterosexual acquisition of HIV in men, and that includes findings from large randomized controlled trials leading to acceptance by the WHO/UNAIDS and the Cochrane Committee, opponents of circumcision continue to generate specious arguments to the contrary. In a recent issue of the Journal of Public Health in Africa, Van Howe and Storms claim that male circumcision will increase HIV infections in Africa. Here we review the statements they use in support of their thesis and show that there is no scientific basis to such an assertion. We also evaluate the statistics used and show that when these data are properly analyzed the results lead to a contrary conclusion affirming the major role of male circumcision in protecting against HIV infection in Africa. Researchers, policy makers and the wider community should rely on balanced scholarship when assessing scientific evidence. We trust that our assessment may help refute the claims by Van Howe and Storms, and provide reassurance on the importance of circumcision for HIV prevention.

\section{Introduction}

In the face of overwhelming evidence to the contrary, Van Howe and Storms argue in $a$ recent article in this journal that there is a lack of scientific evidence, biological plausibility, and epidemiological evidence for male circumcision (MC) as a protection against HIV infection in men. ${ }^{1}$ The article contains, however, unsupported claims, sources that either fail to support or contradict the claims attributed to them, errors in calculations, fallacious reasoning and selective citing of evidence. Previous publications by the first author of the article have been severely criticized. ${ }^{2-8}$ In one of these, involving a meta-analysis of sexually transmitted urethritis, a conclusion that MC would increase this category of STIs arose because the data analyzed differed from that in the source publications; when the actual source data were subjected to a valid metaanalysis by others MC it was found not to increase these STIs. ${ }^{4}$

These are serious problems with potential policy implications deleterious to international public health, and for this reason, a detailed, point-by-point analysis of the key arguments in the article is required. After reading our exposé we trust that readers of the journal will be made aware of our concerns.

\section{The article's Introduction}

The article begins by levelling criticism at an extensive review in 2007 by the WHO/ UNAIDS of the benefits of MC in protection against HIV, ${ }^{9}$ claiming that this contains fundamental flaws that have been glossed over by its proponents within these organizations. We disagree.

\section{Rebuttal of the claim of lack of scientific evidence}

The article then criticizes the three randomized controlled trials (RCTs) whose findings on male circumcision in HIV prevention have been endorsed by the WHO/UNAIDS. ${ }^{10}$ In support of the article's statement that the trials had expectation bias (both researcher and participant), selection bias, lead-time bias, attrition bias, duration bias, and early termination that favored the treatment effect the investigators were hoping for a review in the Lancet ${ }^{11}$ is cited. The latter was, however, published six to eight years before the results of the respective trials were published. ${ }^{12-14}$ The prior observational data suggesting that MC might reduce HIV acquisition in men generated the hypothesis that was tested in the rigorous randomized controlled trials. This cannot be construed as bias. It would be unethical to conduct trials in the absence of a testable hypothesis of potential benefit. The 1999 Lancet review remained silent on the subject of such biases in the trials, and its co-author Halperin had no direct involvement with the trials. In the absence of any justification whatsoever, the
Correspondence: Prof. Brian J. Morris, School of Medical Sciences, University of Sydney, Sydney NSW 2006, Australia.

Tel. +61.2.93513688 - Fax: +61.2.93512227.

E-mail: brian.morris@sydney.edu.au

Key words: circumcision, HIV, epidemiology, evidence-based medicine.

Contributions: BJM, text drafting, coordination of input by co-authors, final formatting; JHW, initial preliminary drafting, calculations, evaluation of text for final draft; RHG, expert intellectual input into content, text revisions; DTH, expert intellectual input, revision of drafts, suggestion of alternative and additional references; RW, expert intellectual input, editing of drafts; BA, expert intellectual input, contribution to text drafting; JK, expert content suggestions, checking of drafts. All authors are in agreement about the content of the final manuscript submitted.

Received for publication: 23 May 2011.

Accepted for publication: 6 July 2011.

This work is licensed under a Creative Commons Attribution NonCommercial 3.0 License (CC BYNC 3.0).

(C) Copyright B.J. Morris et al., 2011

Licensee PAGEPress, Italy

Journal of Public Health in Africa 2011; 2:e28

doi:10.4081/jphia.2011.e28

article then claims that All three studies were overpowered such that the biases alone could have provided a statistically significant difference. This comment reveals a lack of understanding of predetermined trial stopping rules. The three trials were stopped early because formal interim analyses showed greater efficacy than had been anticipated. Thus, rather than indicative bias, the RCT investigators were conservative in their assumptions.

The article then proceeds to attempt to establish that substantial numbers of men in the trials did not acquire HIV through sexual contact. The arguments used are, however, problematic. First, commenting on the South African trial, ${ }^{12}$ the article mistakenly assumes that men who said they had no sexual contact or had always used a condom became infected through non-sexual means. This would make sense only if: (i) condoms were completely effective in preventing HIV transmission; and (ii) self-reported data on condom usage were reliable. In fact, self-reported sexual behavior is often unreliable, ${ }^{15}$ and a realistic estimation of the effectiveness of consistent condom use is $80 \%-90 \%,{ }^{16}$ not more than $99 \%$ as claimed in the article.

The attempt in the article to then subtract these particular men from the trial data for HIV infections is, therefore, misguided. Secondly, commenting on the Ugandan trial, ${ }^{14}$ the article 
notes that men who reported no sexual partners during the follow-up interval of seroconversion accounted for 6 infections, but fails to mention that these infections were evenly distributed between the intervention and control arms. Moreover, these 6 men reported being sexually active in other follow-up intervals, suggesting misreporting. On this basis, the article by Van Howe and Storms calculates that at most 35 of the 67 infections in the Ugandan trial can be attributed to sexual transmission. The basis for this calculation is not given. It would imply that 32 infections cannot be attributed to sexual transmission. This greatly exceeds the figure of 6 reported in their article, suggesting a serious error in calculation. The article makes the same mistake with data from the Kenyan trial, ${ }^{13}$ where 5 men reported no sexual activity before seroconversion, from which the article calculates that 33 infections cannot be attributed to sexual transmission. Thus, in contrast to the conclusion that Conservatively for the three trials, 89 of the 205 infections (43.1\%) were sexually transmitted, the corrected figure is 194 ( $95 \%$ of infections), so invalidating the claim.

No large phase III trial is perfect, and minor anomalies may arise by chance among subgroups. But such trials are designed and powered to address a primary hypothesis in the entire population of participants, not in minor subgroups.

\section{The claim of lack of biological plau- sibility}

In this section, a number of the claims are without foundation. The statement that the mucosa of the inner and outer prepuce have been shown to be of the same thickness misrepresents the source, which studied the thickness of the keratin layer, not that of the entire foreskin tissue. ${ }^{17}$ That study has, moreover, been criticized because the foreskins were from men circumcised for a medical condition that could have affected foreskin histology, the inner mucosa is thicker at the distal end, ${ }^{18}$ and the discrepant results may be attributed to the lack of a standardized method to evaluate keratin thickness, as well as effects of age and other factors on keratin thickness. ${ }^{19}$ This article is also at odds with other authors who were not cited, who reported lower keratinization of the inner foreskin. ${ }^{19-22}$ Furthermore, the statement mucosa of the inner and outer prepuce contradicts the fact that the outer surface of the prepuce is not mucosal.

The article notes that the foreskin's Langerhans cells act as an entry point for HIV, though it misrepresents this as the speculation of unspecified proponents. The article erroneously claims that research has shown that Langerhans cells are quite efficient in repelling $H I V$ and [this] explains why the transmission rate of HIV is one per 1,000 unprotected coital acts. In reality, Langerhans cells act as a target for HIV. ${ }^{19-22}$ Next it is claimed that secretion of the protein langerin by Langerhans cells kills viruses and protect[s] against other sexually transmitted infections. Support for such speculation is not, however, provided. Even if langerin were to be secreted it would not kill viruses. Langerin works by binding HIV after it is sequestered into Langerhans cells, then shunts it to intracellular granules for degradation. ${ }^{23}$ This mechanism becomes overwhelmed at higher viral loads, ${ }^{23,24}$ thus explaining why lack of a foreskin protects against HIV infection.

The claim in the article that its authors have unpublished data to show that circumcised men are at greater risk for STIs contradicts every reliable meta-analysis that has been published in the literature to date, ${ }^{25}$ as well as evidence from the African randomized controlled trials showing MC lowers risk of HSV-2 and HPV infection. ${ }^{26-30}$

In an attempt to refute the argument that the sub-preputial space acts as a harbor for sexually transmitted pathogens, the article claims that Meta-analyses assessing the susceptibility to genital infections with herpes simplex virus and human papilloma virus have not shown an association with circumcision status. Three sources are cited to support this. The first of these reported reduced risk of HSV-2 infection (of borderline statistical significance), chancroid and syphilis. ${ }^{31}$ The second, by Van Howe, ${ }^{32}$ led to criticism by international HPV experts in a critique whose title referred to that article as a biased, inaccurate and misleading meta-analysis. ${ }^{8} \mathrm{~A}$ proper metaanalysis of the same source data showed that circumcision had a substantial protective effect, ${ }^{8}$ as found subsequently in an expanded meta-analysis. ${ }^{25,33}$

The article omits to mention the fact that circumcision changes the flora of the penis, ${ }^{34}$ and that moistness in the space beneath the prepuce increases risk of HIV infection. ${ }^{35} \mathrm{HIV}$ risk increases with foreskin surface area. ${ }^{36} \mathrm{Far}$ from a lack of biological plausibility there are multiple plausible biological explanations for circumcision's protective effect. ${ }^{19,27,37-39}$

\section{Lack of consistent epidemiological evidence}

The article asserts that In Africa, there are several countries where circumcised men are more likely to be HIV infected than intact men, including Malawi, Rwanda, Cameroon, Ghana, Zimbabwe, Lesotho, Swaziland, and Tanzania. This misrepresents the evidence. More correctly, some observational cross-sectional studies in these countries have found such results. However, the overwhelming majority of prospective epidemiological studies suggest that MC is protective. ${ }^{40}$ Additionally, such studies are inherently susceptible to confounding, ${ }^{38}$ and cannot establish causality since circumcision is often performed for medical reasons (frequently recurrent STIs or genital ulcer disease as a consequence of HIV), and so many circumcised men in the studies were already infected prior to circumcision. ${ }^{41}$

It is claimed that If the national survey data that are available from 19 countries are combined in a meta-analysis (Table 1) the randomeffects model summary effect for the risk of a genitally intact man having HIV is an odds ratio of $1.10(95 \% \mathrm{CI}=0.83-1.46)$, indicating that on a general population level, circumcision has no association with risk of HIV infection. Here the article's analysis contradicts previously published analyses of such data. For example, a study of data from 18 studies in sub-Saharan Africa by Gebremedhin found a protective effect of circumcision which was strengthened when adjusted for number of lifetime partners, sexual behavior, age, place of residence (urban/rural), educational status, marital status, comprehensive knowledge towards HIV/AIDS and frequency of use of mass media (OR of 4.95, 95\% CI 4.57-5.36 for uncircumcised vs. circumcised men). ${ }^{42}$

The article further asserts that Among developed nations, the United States has the highest rate of circumcision and the highest rate of heterosexually transmitted HIV. While it is true that the US has higher HIV prevalence than many developed countries, it is not true that it has the highest. ${ }^{43}$ HIV left Africa and arrived in the USA, via Haiti, ${ }^{44}$ earlier than the rest of the world, so has had more time to spread. More importantly, between-country comparisons of aggregate data represent one of the weakest of all analyses because of their failure to isolate the effect of the parameter that is being studied, as Van Howe himself acknowledged in 1999. ${ }^{45}$ And even then, for 38 developing countries in which heterosexual acquisition is the major mode of HIV infection, UNAIDS data have shown HIV prevalence to be $16 \%$ for the 8 countries with low $(<20 \%)$ MC rates and $3 \%$ for the 22 with high $(>80 \%)$ MC rates. ${ }^{46}$ The US has relatively poor levels of sex education and consequent condom usage, ${ }^{47-50}$ which might reasonably be expected to act as a confounding factor. Most importantly, in the developed world most HIV infections occur through receptive anal sex and injecting drug use, neither of which is influenced by circumcision status. Interestingly, however, there is evidence to suggest that, when using male-tofemale transmission as a baseline, female-tomale transmission (which MC is known to protect against) is far lower in the USA than in Europe. ${ }^{51}$

The article goes on to claim that Within the United States, blacks have the highest rate of 
circumcision and the highest rate of heterosexually transmitted HIV. Four sources are cited in support of the claim regarding circumcision rates by race, and it is instructive to examine them. Two are concerned with neonatal circumcision, not the prevalence of circumcision among adults. ${ }^{52,53}$ Even so, one of the sources cited actually contradicts the authors' claim, reporting that $89.6 \%$ of whites were circumcised versus $86.9 \%$ of African Americans. ${ }^{53}$ The latter is not a nationally representative sample, nor is the third source cited. ${ }^{54}$ These thus fail to support the article's claim, as does the only nationally-representative study of adults which found MC prevalence was $88 \%$ in non-Hispanic whites, $73 \%$ in non-Hispanic blacks, $42 \%$ in Mexican Americans, and $50 \%$ in others. ${ }^{55}$ Similarly, another nationally-representative study of adults reported that in particular, whites are considerably more likely to be circumcised than are blacks or Hispanics $(81 \%$ vs $65 \%$ or $54 \%) .56$

We, therefore, find it astonishing that such a bold claim can be made using sources that state the opposite to support it.

\section{Risk compensation}

The article confidently predicts that Risk compensation will accompany the circumcision solution in Africa. Here the article ignores the fact that this issue has been studied extensively, and research generally indicates little or no risk compensation. ${ }^{57}$ It then goes on to make various unsubstantiated assumptions, including one that condoms are $98 \%$ effective, to calculate that the impact of a fifteen-fold increase in the rate of circumcision could be accompanied by a relative $41 \%$ increase in the use of condoms. The fifteen-fold figure is repeated at the end of the next section of the article following further questionable statistics (discussed below).

\section{Leap of faith}

The assertion that Interventions and medications that demonstrate efficacy in a research setting are often failures in a clinical setting. Circumcision will provide another example of this is incorrect, having no evidence to support it. Van Howe once predicted that it was unlikely that a trial would find a protective effect of circumcision against HIV. ${ }^{58}$

The article's claim that the association between circumcision status and HIV infection was present primarily in studies of high-risk men misrepresents the literature. The association is in fact seen in most settings and, as the 2003 Cochrane review put it, The results from existing observational studies show a strong epidemiological association between male circumcision and prevention of HIV, especially among high-risk groups. ${ }^{59}$ Most recently, the Cochrane Committee conducted a very exten- sive analysis of the trial data, leading them to state inclusion of male circumcision into current HIV prevention guidelines is warranted and no further trials are required. ${ }^{60}$

The next claim is that observational studies of general populations have for the most part failed to show an association between circumcision status and HIV infection. Nothing could be further from the truth. Of the three sources cited, one is a single 16-year old observational study ${ }^{61}$ which did not fully adjust for potentially confounding factors such as greater number of sexual partners and higher circumcision rate amongst men in the upper strata of Tanzanian society. The second contradicts the article's claim, since that study reports an intact foreskin was associated with an increased risk of HIV infection: combined odds ratio 1.43 (1.32 to 1.54) with a fixed effect model and 1.67 (1.25 to 2.24) with a random effect model. ${ }^{6}$ The third source cited is a metaanalysis by Van Howe, which was the subject of severe criticism $^{6,7}$ for its inappropriate methodology leading to an erroneous conclusion. A recent textbook on meta-analyses discusses in detail this particular meta-analysis as an illustrative example of how Simpson's paradox can lead to incorrect results. ${ }^{62}$ Similarly, a review of methods and techniques in meta-analysis noted that Although this [Simpson's] paradox is usually illustrated with hypothetical examples, in one meta-analysis [Van Howe's] that used simple data pooling to test the protective effect of circumcision against AIDS infection in sub-Saharan African men, conclusions were reached that were diametrically opposed to those of a subsequent meta-analysis in which appropriate techniques were used. ${ }^{63}$

It is noteworthy that every correctly-performed meta-analysis of observational studies of MC and HIV has reported a protective effect. For example, like the Cochrane Committee, ${ }^{59}$ Weiss et al. reported that male circumcision is associated with a significantly reduced risk of HIV infection among men in sub-Saharan Africa, particularly those at high risk of HIV. ${ }^{40}$ A later as-treated meta-analysis of the 15 observational studies that adjusted for potential confounders found a protective effect of $65 \%$, this being identical to the $65 \%$ figure obtained from a meta-analysis of the initial findings of the three randomized controlled trials. $^{37}$ Another meta-analysis, of 13 studies, $85 \%$ of which were from sub-Saharan Africa, reported a $53 \%$ protective effect for general populations and $69 \%$ for high-risk populations. ${ }^{64}$ If MC status was ascertained by selfreport the protective effect was $45 \%$, but if by direct genital examination in the clinic it was 65\%. ${ }^{64}$ These particular authors pointed out that the current data on MC satisfy 6 of the 9 criteria of causality as outlined by Sir A.B. Hill, namely strength of association, consistency, temporality, coherence, biological plausibility, and experiment. 65

The article then asserts that there is no scientific reason to believe that the RCT results would necessarily apply to the general population. While we agree that circumcision might not affect monogamous partnerships, how can the article explain UNAIDS data showing a strong inverse correlation between circumcision rate in general populations and HIV prevalence ${ }^{46}$ So the claim that increasing condom use from $48 \%$ up to $51.8 \%$ would result in the same gains as increasing the circumcision rate from $5 \%$ up to $75 \%$ should be seriously questioned.

\section{Attractive, less invasive, less expensive, more effective alterna- tives}

In this section, the article starts out by citing Gisslequist et al. saying that most infections can be attributed to non-sexual transmission. The arguments by those authors have, however, been shown to be fallacious. ${ }^{66}$ While anti-retroviral therapy has prolonged the lives of those infected with HIV, the cost is enormous, making it unaffordable and unsustainable in developing countries. ${ }^{67}$ Moreover, prevention of infection is preferable to compliance with a strict regimen of daily medication.

Even though the test-and-treat model the article proposes is based on a study in Africa, its cost makes it beyond the reach of generalized populations in Africa. In countries such as the USA, poor engagement in care for HIVinfected individuals will substantially limit the effectiveness of test-and-treat strategies. ${ }^{68}$ What's more, The belief that having an undetectable viral load leads to lower infectiousness was associated with [a] greater number of partners, including nonpositive partners, and less condom use, ${ }^{69}$ so that programs aimed at testing and treating people living with HIV/AIDS for prevention require attention to adherence and sexual behavior. ${ }^{69}$

It is then claimed that many HIV experts consider primary prevention extremely wasteful and ineffective So why then is so much effort going into developing a prophylactic vaccine against HIV? And why are governments spending billions vaccinating school girls against the two types of HPV that cause $70 \%$ of cervical cancers, when only a tiny proportion of those girls, a proportion which is impossible to identify individually in advance, will go on to get cervical cancer later in life? ${ }^{70,71}$

The article then criticizes modeling by the WHO and others that has demonstrated the enormous savings in lives and costs from increasing $\mathrm{MC}$ in high prevalence settings. ${ }^{72}$ In so doing, they allude to the possibility that the findings over the 1.5-2 years of the trials 
will not hold up over the longer term. In fact by 4.5-5 years effectiveness has now been shown to have increased. ${ }^{73,74}$ Even in low prevalence settings such as the USA, infant circumcision has been shown to be cost-saving for HIV prevention. ${ }^{75}$ Furthermore, the suggestion that condoms will be cheaper has to assume that funding for the extremely low 2.5 cents cost per condom will persist in poverty-stricken HIV-ravaged countries. On average, condom use is at best inconsistent even in developed countries where people can afford them. ${ }^{76-80}$ In the trials, condoms were provided free and participants received regular counseling, but their use was low. ${ }^{13,81}$ In Africa the association between condom use and HIV is, moreover, complex. ${ }^{16,82,83}$ The article cites one of Van Howe's publications that concluded that circumcision removes the most sensitive part of the penis, ${ }^{84}$ failing to point out that a reanalysis of the data from that study disproved its conclusions. ${ }^{2}$ The article also chose not to refer to the bulk of the literature ${ }^{39}$ including RCT data that means show either no difference $^{85}$ or improvement ${ }^{86}$ in sensitivity in circumcised men.

Near the end of the article we see more unsubstantiated claims such as with the push for circumcision, public health workers in Africa are finding that resources that previously paid for condoms are now being redirected to circumcision. With every circumcision performed, 3000 condoms will not be available and that a health care provider is prevented from caring for someone in need of medical care and so on. Such fear-mongering is unhelpful and seems based more on ideological opposition to circumcision per se than on any sober and objective analysis of the existing scientific evidence.

\section{Conclusions}

Our critique of Van Howe and Storms' article has highlighted some of the more audacious claims therein. Other claims not addressed here are even more transparently incorrect, being based on assumptions or idealistic, but unsubstantiated, optimism devoid of evidential support. In consideration of all these factors, we find that publication of this paper is quite unhelpful to international objectives aimed at stemming the epidemic of HIV, at least as far as heterosexual transmission is concerned, and especially in high prevalence settings such as sub-Saharan Africa. The level of protection deemed acceptable for vaccines against influenza ${ }^{87,88}$ justifies claims that infant MC can be regarded as a surgical vaccine..$^{39,89,90}$ But we emphasize that it should be seen as part of a comprehensive package that includes promoting changes in behavior, the use of condoms, and other important prevention approaches. Just as both airbags (which are always in place) and seatbelts (which need to be applied each time) are needed, both circumcision and changes in behavior should be promoted to help alleviate the spread of HIV worldwide..$^{91}$

\section{References}

1. Van Howe RS, Storms MR. How the circumcision solution in Africa will increase HIV infections. J Publ Health Africa 2011;2:e4.

2. Waskett JH, Morris BJ. Fine-touch pressure thresholds in the adult penis. (Critique of Sorrells ML, et al. BJU Int 2007;99:864-869). BJU Int 2007;99:1551-2.

3. Waskett JH, Morris BJ. Re: 'RS Van Howe, FM Hodges. The carcinogenicity of smegma: debunking a myth.' An example of myth and mythchief making? (Letter to the Editor). J Eur Acad Dermatol Venereol 2008;22:131.

4. Waskett JH, Morris BJ, Weiss HA. Errors in meta-analysis by Van Howe. Int J STD AIDS 2009;20:216-8.

5. Schoen EJ. Critique of Van Howe RS. Incidence of meatal stenosis following neonatal circumcision in a primary care setting. Clin Pediatr (Phila) 2006;45:4954. Clin Pediatr (Phila) 2007;46:86.

6. O'Farrell N, Egger M. Circumcision in men and the prevention of HIV infection: a 'meta-analysis' revisited. Int J STD AIDS 2000;11:137-42.

7. Moses S, Nagelkerke NJD, Blanchard JF. Commentary: Analysis of the scientific literature on male circumcision and risk for HIV infection. Int J STD AIDS 1999;10:6268.

8. Castellsague X, Albero G, Cleries R, Bosch FX. HPV and circumcision: A biased, inaccurate and misleading meta-analysis. $\mathrm{J}$ Infect 2007;55:91-3.

9. World Health Organization/UNAIDS. Male circumcision: Global trends and determinants of prevalance, safety and acceptability. http://whqlibdoc.who.int/publications/2007/9789241596169_eng.pdf. Geneva: World Health Organization; 2007.

10. World Health Organization, UNAIDS. New data on male circumcision and HIV prevention: policy and programme implications. 2007:http://who.int/hiv/mediacentre/MCrecommendations_en.pdf.

11. Halperin D, Bailey R. Male circumcision and HIV infection: 10 years and counting. Lancet 1999;354:1813-5.

12. Auvert B, Taljaard D, Lagarde E, et al. Randomized, controlled intervention trial of male circumcision for reduction of HIV infection risk: The ANRS 1265 Trial. PLoS Med. 2005;2:e298.

13. Bailey RC, Moses S, Parker CB, et al. Male circumcision for HIV prevention in young men in Kisumu, Kenya: a randomised controlled trial. Lancet 2007;369:643-56.

14. Gray RH, Kigozi G, Serwadda D, et al. Male circumcision for HIV prevention in men in Rakai, Uganda: a randomised trial. Lancet 2007;369:657-66.

15. Minnis AM, Steiner MJ, Gallo MF, et al. Biomarker validation of reports of recent sexual activity: results of a randomized controlled study in Zimbabwe. Am J Epidemiol 2009;170:918-24.

16. Hearst N, Chen S. Condom promotion for AIDS prevention in the developing world: is it working? Stud Fam Plann 2004;35:3947.

17. Dinh MH, McRaven MD, Kelley Z, et al. Keratinization of the adult male foreskin and implications for male circumcision. AIDS 2010;24:899-906.

18. Gray RH, Bailey RC, Morris BJ. [Comment on] Keratinization of the adult male foreskin and implications for male circumcision. AIDS 2010;24:1381.

19. Ganor Y, Bomsel M. HIV-1 transmission in the male genital tract. Am J Reprod Immunol 2011;65:284-91.

20. Patterson BK, Landy A, Siegel JN, et al. Susceptibility to human immunodeficiency virus-1 infection of human foreskin and cervical tissue grown in explant culture. Am J Pathol 2002;161:867-73.

21. McCoombe SG, Short RV. Potential HIV-1 target cells in the human penis. AIDS. 2006;20:1491-5.

22. Ganor Y, Zhou Z, Tudor D, et al. Within $1 \mathrm{~h}$, HIV-1 uses viral synapses to enter efficiently the inner, but not outer, foreskin mucosa and engages Langerhans-T cell conjugates. Mucosal Immunol 2010;3:50622.

23. de Witte L, Nabatov A, Pion M, et al. Langerin is a natural barrier to HIV-1 transmission by Langerhans cells. Nat Med 2007;13:367-71.

24. Schwartz 0. Langerhans cells lap up HIV-1. Nat Med 2007;13:245-6.

25. Bosch FX, Albero G, Castellsagué X. Male circumcision, human papillomavirus and cervical cancer: from evidence to intervention. J Fam Plann Reprod Health Care 2009;35:5-7.

26. Tobian AAR, Serwadda D, Quinn TC, et al. Male circumcision for the prevention of HSV-2 and HPV infections and syphilis. N Engl J Med. 2009;360:1298-309.

27. Gray RH, Wawer MJ, Serwadda D, Kigozi G. The role of male circumcision in the prevention of human papillomavirus and HIV infection. J Infect Dis 2009;199:1-3. 
28. Sobngwi-Tambekou J, Taljaard D, Lissouba P, et al. Effect of HSV-2 serostatus on acquisition of HIV by young men: results of a longitudinal study in Orange Farm, South Africa. J Infect Dis 2009;199:958-64.

29. Auvert B, Sobngwi-Tambekou J, Cutler E, et al. Effect of male circumcision on the prevalence of high-risk human papillomavirus in young men: results of a randomized controlled trial conducted in orange farm, South Africa. J Infect Dis 2009;199:14-9.

30. Backes DM, Bleeker MC, Meijer CJ, et al. Male circumcision is associated with a lower prevalence of human papillomavirus-associated penile lesions among Kenyan men. Int J Cancer. 2011:May 26 [Epub ahead of print].

31. Weiss HA, Thomas SL, Munabi SK, Hayes RJ. Male circumcision and risk of syphilis, chancroid, and genital herpes: a systematic review and meta-analysis. Sex Transm Infect. 2006;82:101-109.

32. Van Howe RS. Human papillomavirus and circumcision: a meta-analysis. J Infect. 2007;54:490-496.

33. Morris BJ, Gray RH, Castellsague X, Bosch FX, Halperin DT, Waskett JH, Hankins CA. The strong protection afforded by circumcision against cancer of the penis. (Invited Review). Adv Urol 2011(Article ID 812368):1-21

34. Price LB, Liu CM, Johnson KE, et al. The effects of circumcision on the penis microbiome. PLOS ONE. 2010;5:e8422.

35. O'Farrell N, Morison L, Moodley P, et al. Association between HIV and subpreputial penile wetness in uncircumcised men in South Africa. J Acquir Immune Defic Syndr 2006;43:69-77.

36. Kigozi G, Wawer M, Ssettuba A, et al. Foreskin surface area and HIV acquisition in Rakai, Uganda (size matters). AIDS 2009;23:2209-13.

37. Weiss HA, Halperin D, Bailey RC, Hayes RJ, Schmid G, Hankins CA. Male circumcision for HIV prevention: from evidence to action? (Review). AIDS. 2008;22:567-574.

38. Wamai RG, Weiss HA, Hankins C, et al. Male circumcision is an efficacious, lasting and cost-effective strategy for combating HIV in high-prevalence AIDS epidemics: Time to move beyond debating the science. Future HIV Ther 2008;2:399-405.

39. Morris BJ. Why circumcision is a biomedical imperative for the 21st century. BioEssays 2007;29:1147-58.

40. Weiss HA, Quigley MA, Hayes RJ. Male circumcision and risk of HIV infection in subSaharan Africa: a systematic review and meta-analysis. AIDS 2000;14:2361-70.

41. Halperin DT, Weiss HA, Hayes R, et al. Response to Ronald Gray, Male circumcision and HIV acquisition and transmis- sion: cohort studies in Rakai, Uganda (2000, 14:2371-2381). AIDS 2002;16:810-2.

42. Gebremedhin S. Assessment of the protective effect of male circumcision from HIV infection and sexually transmitted diseases: evidence from 18 demographic and health surveys in sub-Saharan Africa. Afr J Reprod Health 2010;14:105-13.

43. Central Intelligence Agency. The World Factbook. Country Comparison: HIV/AIDS Adult Prevalence Rate. Available at: https://www.cia.gov/library/publications/th e-world-factbook/rankorder/2 155 rank.html. Accessed May 11, 2011.

44. Gilbert MT, Rambaut A, Wlasiuk G, et al. The emergence of HIV/AIDS in the Americas and beyond. Proc Natl Acad Sci USA 2007;104:18566-70.

45. Van Howe RS. Circumcision and HIV infection: review of the literature and metaanalysis. Int J STD AIDS 1999;10:8-16.

46. Drain PK, Halperin DT, Hughes JP, et al. Male circumcision, religion, and infectious diseases: an ecologic analysis of 118 developing countries. BMC Infect Dis 2006;6:172.

47. Michael RT, Wadsworth J, Feinleib J, et al. Private sexual behavior, public opinion, and public health policy related to sexually transmitted diseases: a US-British comparison. Am J Public Health 1998;88:74954.

48. Weinberg MS, Lottes IL, Aveline D. AIDS risk reduction strategies among United States and Swedish heterosexual university students. Arch Sex Behav 1998;27:385401.

49. Brick P. How does Europe do it? Fam Life Matters 1999;36:3.

50. Dodge B, Sandfort TG, Yarber WL, de Wit J. Sexual health among male college students in the United States and the Netherlands. Am J Health Behav 2005;29:172-82.

51. Bailey RC, Halperin DT. Male circumcision and HIV infection. Lancet 2000;355:927.

52. O'Brien TR, Calle EE, Poole WK. Incidence of neonatal circumcision in Atlanta, 19851986. Southern Med J 1995;88:411-5.

53. Mansfield CJ, Hueston WJ, Rudy M. Neonatal circumcision: associated factors and length of hospital stay. J Fam Pract 1995;41:370-6.

54. Mor Z, Kent CK, Kohn RP, Klausner JD. Declining rates in male circumcision amidst increasing evidence of its public health benefit. PLoS ONE 2007;2:e861.

55. Xu F, Markowitz LE, Sternberg MR, Aral SO. Prevalence of circumcision and herpes simplex virus type 2 infection in men in the United States: the National Health and Nutrition Examination Survey (NHANES), 1999-2004. Sex Transm Dis 2007;34:47984.
56. Laumann EO, Maal CM, Zuckerman EW. Circumcision in the United States. Prevalence, prophyactic effects, and sexual practice. J Am Med Assoc 1997;277:10527.

57. Mattson CL, Campbell RT, Bailey RC, et al. Risk compensation is not associated with male circumcision in Kisumu, Kenya: a multi-faceted assessment of men enrolled in a randomized controlled trial. PLOS ONE 2008;3:e2443.

58. Van Howe RS, Svoboda JS, Hodges FM. HIV infection and circumcision: cutting through the hyperbole. J R Soc Promot Health 2005;125:259-65.

59. Siegfried N, Muller M, Volmink J, et al. Male circumcision for prevention of heterosexual acquisition of HIV in men. Cochrane Database Syst Rev 2003:CD 003362.

60. Siegfried N, Muller M, Deeks JJ, Volmink J. Male circumcision for prevention of heterosexual acquisition of HIV in men. Cochrane Database Syst Rev 2009;CD0 03362 (38 pp).

61. Grosskurth H, Mosha F, Todd J, et al. A community trial of the impact of improved sexually transmitted disease treatment on the HIV epidemic in rural Tanzania: 2. Baseline survey results. AIDS 1995;9:92734.

62. Borenstein M, Hedges L, Higgins JPT, Rothstein HR. Introduction to MetaAnalysis. 2009, John Wiley \& Sons, West Sussex, UK.

63. Barker FG 2nd, Carter BS. Synthesizing medical evidence: systematic reviews and metaanalyses. Neurosurg Focus 2005;19: e5.

64. Byakika-Tusiime J. Circumcision and HIV infection: assessment of causality. AIDS Behav 2008;12:835-41.

65. Hill BA. The environment and disease: Association or causation? Proc Royal Soc Med. 1965;58:295-300.

66. Wamai R, Morris BJ. 'How to contain generalized HIV epidemics' article is misconstrued. Int J STD AIDS 2011;22:415-6.

67. Quinn TC, Serwadda D. The future of HIV/AIDS in Africa: a shared responsibility. Lancet 2011;377:1133-4.

68. Gardner EM, McLees MP, Steiner JF, et al. The spectrum of engagement in HIV care and its relevance to test-and-treat strategies for prevention of HIV infection. Clin Infect Dis 2011;52:793-800.

69. Kalichman SC, Cherry C, Amaral CM, et al. Adherence to antiretroviral therapy and HIV transmission risks: implications for test-and-treat approaches to HIV prevention. AIDS Patient Care STDS 2010;24:2717.

70. Morris BJ, Rose BR. Cervical screening in the 21st century: the case for human papil- 
lomavirus testing of self-collected specimens. Clin Chem Lab Med 2007;45:577-91.

71. Clifford G, Franceschi S, Diaz M, et al. HPV type-distribution in women with and without cervical neoplastic diseases. Vaccine 2006;24(Suppl 3):26-34.

72. Williams BG, Lloyd-Smith J0, Gouws E, et al. The potential impact of male circumcision on HIV in Sub-Saharan Africa. PLoS Med 2006;3:e262

73. Bailey RC, Moses S, Parker CB, et al. The protective effect of adult male circumcision against HIV acquisition is sustained for at least 54 months: results from the Kisumu, Kenya trial. XVIII International AIDS Conference, Jul 18-23, 2010, Vienna, Austria, Abstract \#FRLBC1.

74. Kong X, Kigozi G, Ssempija V, et al. Longerterm effects of male circumcision on HIV incidence and risk behaviors during posttrial surveillance in Rakai, Uganda. 18th Conference on Retroviruses and Opportunistic Infections, Feb 27-Mar 2, 2011, Boston, MA, USA, Abstract\#36.

75. Sansom SL, Prabhu VS, Hutchinson AB, et al. Cost-effectiveness of newborn circumcision in reducing lifetime HIV risk among U.S. males. PLoS One 2010;5:e8723.

76. Sanchez T, Finlayson T, Drake A, et al. Human immunodeficiency virus (HIV) risk, prevention, and testing behaviors-United States, National HIV Behavioral Surveillance System: men who have sex with men, November 2003-April 2005. MMWR Surveill Summ 2006;55:1-16.
77. Beckman LJ, Harvey SM, Tiersky LA. Attitudes about condoms and condom use among college students. J Am Coll Hlth 1996;44:243-9.

78. Anderson JE, Wilson R, Doll L, et al. Condom use and HIV risk behaviors among US adults: data from a national survey. Fam Plann Perspect 1999;31:24-8.

79. Jadack RA, Yuenger J, Ghanem KG, Zenilman J. Polymerase chain reaction detection of Y-chromosome sequences in vaginal fluid of women accessing a sexually transmitted disease clinic. Sex Transm Dis 2006;33:22-5.

80. Kang M, Rochford A, Johnston V, et al. Prevalence of Chlamydia trachomatis infection among 'high risk' young people in New South Wales. Sex Health 2006;3: 253-4.

81. Wawer MJ, Makumbi F, Kigozi G, et al. Circumcision in HIV-infected men and its effect on HIV transmission to female partners in Rakai, Uganda: a randomised controlled trial. Lancet 2009;374:229-37.

82. Slaymaker E. A critique of international indicators of sexual risk behaviour. Sex Transm Infect 2004;80(Suppl 2):ii13-21.

83. Lopman B, Nyamukapa C, Mushati P, et al. HIV incidence in 3 years of follow-up of a Zimbabwe cohort--1998-2000 to 2001-03: contributions of proximate and underlying determinants to transmission. Int J Epidemiol 2008;37:88-105.

84. Sorrells ML, Snyder JL, Reiss MD, et al. Fine-touch pressure thresholds in the adult penis. BJU Int 2007;99:864-9.

85. Kigozi G, Watya S, Polis CB, et al. The effect of male circumcision on sexual satisfaction and function, results from a randomized trial of male circumcision for human immunodeficiency virus prevention, Rakai, Uganda. BJU Int 2008;101:6570.

86. Krieger JN, Mehta SD, Bailey RC, et al. Adult male circumcision: Effects on sexual function and sexual satisfaction in Kisumu, Kenya. J Sex Med 2008;5:2610-22.

87. Fiore AE, David K. Shay DK, et al. Prevention and Control of Influenza. Recommendations of the Advisory Committee on Immunization Practices (ACIP), 2007. Centers for Disease Control and Prevention - Mortality and Morbidity Weekly Report 2007;56:1-54.

88. Kelly H, Carville K, Grant K, et al. Estimation of influenza vaccine effectiveness from routine surveillance data. PLoS One 2009;4:e5079.

89. Schoen EJ. Circumcision as a lifetime vaccination with many benefits. J Men's Hlth Gender 2007;382:306-11.

90. Ben KL, Xu JC, Lu L, et al. Male circumcision is an effective "surgical vaccine" for HIV prevention and reproductive health. Zhonghua Nan Ke Xue 2009;15:395-402 [Article in Chinese].

91. Cooper DA, Wodak AD, Morris BJ. The case for boosting infant male circumcision in the face of rising heterosexual transmission of HIV. Med J Aust 2010;193:318-9. 